Article

\title{
Environmental Issues as Drivers for Food Choice: Study from a Multinational Framework
}

\author{
Raquel P. F. Guiné ${ }^{1, *(\mathbb{D})}$, Elena Bartkiene ${ }^{2} \mathbb{D}$, Sofia G. Florença ${ }^{3}$, Ilija Djekić 4 (D), Maša Černelič Bizjak ${ }^{5}(\mathbb{D}$, \\ Monica Tarcea ${ }^{6}{ }^{D}$, Marcela Leal ${ }^{7}$, Vanessa Ferreira ${ }^{8}$, Ivana Rumbak ${ }^{9}$ D, Panagiotis Orfanos ${ }^{10}$, Viktória Szúcs ${ }^{11}$, \\ Dace Klava $^{12}$, Małgorzata Korzeniowska ${ }^{13}$, , Kathy Isoldi ${ }^{14}$, Paula Correia ${ }^{1}$, Manuela Ferreira ${ }^{15}$ \\ and Ana Paula Cardoso 16
}

check for updates

Citation: Guiné, R.P.F.; Bartkiene, E.; Florença, S.G.; Djekić, I.; Bizjak, M.Č.; Tarcea, M.; Leal, M.; Ferreira, V.; Rumbak, I.; Orfanos, P.; et al. Environmental Issues as Drivers for Food Choice: Study from a Multinational Framework. Sustainability 2021, 13, 2869. https:// doi.org/10.3390/su13052869

Academic Editors: Amélia Martins Delgado and Marc A. Rosen

Received: 27 January 2021

Accepted: 2 March 2021

Published: 6 March 2021

Publisher's Note: MDPI stays neutral with regard to jurisdictional claims in published maps and institutional affiliations.

Copyright: (c) 2021 by the authors. Licensee MDPI, Basel, Switzerland. This article is an open access article distributed under the terms and conditions of the Creative Commons Attribution (CC BY) license (https:/ / creativecommons.org/licenses/by/ $4.0 /)$.
1 CERNAS-IPV Research Centre and Department Food Industry, Polytechnic Institute of Viseu, 3504-510 Viseu, Portugal; paulacorreia@esav.ipv.pt

2 Department of Food Safety and Quality, Lithuanian University of Health Sciences, 44307 Kaunas, Lithuania; elena.bartkiene@1smuni.lt

3 Faculty of Food and Nutrition Sciences, University of Porto, 4200-465 Porto, Portugal; sofiaguine@gmail.com

4 Faculty of Agriculture, University of Belgrade, 11000 Belgrade, Serbia; idjekic@agrif.bg.ac.rs

5 Faculty of Health Sciences, University of Primorska, 6310 Izola, Slovenia; Masa.Cernelic@fvz.upr.si

6 Department Community Nutrition and Food Safety, George Emil Palade University of Targu Mures, 540141 Targu-Mures, Romania; monica.tarcea@umftgm.ro

7 School of Nutrition, Faculty of Health Sciences, Maimonides University, C1405 Buenos Aires, Argentina; leal.nutricion@gmail.com

8 Department of Nutrition, University UFVJM-FCBS, 39100-000 Diamantina, Minas Gerais, Brazil; vanessa.nutr@gmail.com

9 Faculty of Food Technology and Biotechnology, University of Zagreb, 10000 Zagreb, Croatia; icecic@pbf.hr

10 International Hellenic University, Department of Food Science and Technology, 57400 Thessaloniki, Greece; panagiotis.orfanos94@gmail.com

11 Directorate of Food Industry, Hungarian Chamber of Agriculture, H111 Budapest, Hungary; szucs.viktoria@nak.hu

12 Faculty of Food Technology, Latvian University of Agriculture, LV 3001 Jelgava, Latvia; dace.klava@llu.lv

13 Wrocław University of Environmental and Life Sciences, 51-630 Wrocław, Poland; malgorzata.korzeniowska@upwr.edu.pl

14 Department of Nutrition, University of Long Island, New York, NY 11548-1327, USA; kathy.isoldi@liu.edu

15 UNICISA:E Research Centre and School of Health, Polytechnic Institute of Viseu, 3504-510 Viseu, Portugal; mmcferreira@gmail.com

16 CI\&DEI Research Centre and School of Education, Polytechnic Institute of Viseu, 3504-510 Viseu, Portugal; a.p.cardoso@esev.ipv.pt

* Correspondence: raquelguine@esav.ipv.pt 
sustainable food choices on a number of countries and how people shape their food choices according to some sustainability issues.

Keywords: food choice; food waste; sustainable agriculture; sustainable packaging

\section{Introduction}

Food supply chains are main targets for the sustainable development goals (SDGs) of the United Nations, since the growing world population constantly needs food that must be produced, transformed, packed, transported, stored, and disposed in sustainable ways [1,2]. The United Nations has established in 2015 the 2030 Agenda for Sustainable Development, accounting for 17 SDGs and 169 sustainable specific targets, indicators, and metrics. In particular, goal 12 (Responsible consumption and production) applies to all phases of the food supply chain [1,2].

Knowing that the world population is estimated to be nearly 10 billion by the year 2050, the food supply demand will raise by 70\% [3]. This immense growth of the human population poses a significant number of challenges, related with many different aspects that go from the food supply chain until the global public health [4]. These challenges include efficient food production, availability of foods at global level, responsible use of land and water, efficient management of natural resources, minimization of environmental impacts, maximization of nutritive value of foods and, finally, management of the use of chemical residues and harmful substances (such as pesticides, for example) with impact on the natural ecosystems and human health [4-6].

O'Neill et al. [7] discuss that none of the world's countries are, in light of the present situation, readily prepared to face the critical needs for human nourishing, while also preserving the environment and keep the ecosystems sustainable. On the other hand, it is also true that about one third of the food produced in the world is lost every day. These wasted food products imply that the resources used in their production and distribution along the food supply chain are also being wasted, like for example, fuel, soil nutrients, water, fertilisers, pesticides, raw materials or packaging [3].

The agri-food supply chain challenges for sustainable development are not only related with the food products themselves, but also include economic, environmental, and social aspects [8]. Societies are changing all over the world [8,9]. In developed countries modifications are observed towards a more consumer focused approach and in developing countries arising wider markets and opportunities for growth [10,11]. Along with these modifications, the patterns of consumption in developed and developing countries are increasing, demanding for more food. This also implies that the food industries around the world increase the amounts of waste and greenhouse gas (GHG) [8].

However, presently, the consumers are already more conscientious of these issues and some of them even tend to shape their food choices towards a higher global sustainability. A study conducted in Egypt [12] showed that consumer's choices towards sustainable foods are influenced by attitudes, perceived behavioural control, personal standards and activism. Iris et al. [13] investigated the relationship between food choice and consumer preferences for sustainable foods in Israel. Their results showed that depending on the dietary patterns, people may be more prone to make environmentally friendly choices, such as, for example, vegans. Dowd and Burke [14] evaluated the intentions to purchase sustainable foods and their results showed that from the 8 food choice motivations studied, only health and ethical values significantly influenced the intention to buy sustainable food products. These works confirm that people make different food choices in alignment with sustainable goals. Presently, consumers are much influenced by marketing, which is designed to successful businesses, but, if targeted to motivate sustainable food choices, it could represent an important shift towards expansion of the sustainable food chains [12]. 
In 2019 food choices were the motto for the EAT-Lancet Commission to take a stand and produce a global alert towards sustainability at global level [15]. This commission is non-profit think-tank that includes 37 prominent scientists originating from 16 countries, which are experts in areas such human health, political sciences, agriculture and environmental sustainability. They published an urgent call for "planetary health diets", aimed at improving human health while at the same time coping with environmental sustainability [15]. It is, however, imperative what lies behind the concept of a sustainable healthy diet, and to this matter is worthy to mention the reference provided by a joint release from the Food and Agriculture organization of the United Nations and the World Health Organization (FAO/WHO) [16] for the guiding principles for what constitutes "Sustainable Healthy Diets", which include two dimensions-sustainability and healthiness of diets. These guiding principles are aligned with the sustainable development goals of the United Nations, particularly goals 1 (No Poverty), 2 (Zero Hunger), 3 (Good Health and Well-Being), 4 (Quality Education), 5 (Gender Equality), 12 (Responsible Consumption and Production) and 13 (Climate Action) [16]. According to the EAT-Lancet Commission [15] a healthy reference diet consists mostly of vegetables, fruits, whole grains, legumes, nuts and unsaturated oils; it also includes a low to moderate amount of seafood and poultry, but excludes or includes in low quantities the following foods: red meat, processed meat, added sugar, refined grains and starchy vegetables. Fardet and Rock [17] referred that a French diet called the "3V rule" (standing for vegetable, real and varied and whenever possible organic, local and seasonal) provides all nutritional needs. Additionally, this model could be transposed to other contexts, and adapted according to regional traditions and environmental characteristics. However, they alert that by excluding even only one dimension, could set at risk the health as well as the sustainability of the food system [17]. Hence, the adoption of this $3 \mathrm{~V}$-based diet, with respect for local constraints, would preserve the human health and also the environment (greenhouse gas emissions, pollution, deforestation, etc.), small farmers, animal welfare and biodiversity, culinary traditions and socioeconomics (including an alleviation of public health cost) [17].

Some studies have demonstrated that sociodemographic factors influence people's food behaviour in what concerns sustainability. Feil et al. [18] investigated the relation between some socioeconomic and demographic factors on the motivations to consume organic foods among Brazilians. Their results showed complex interactions between consumer motivations and attitudes towards organic food. Additionally, Funk et al. [19] studied the environmentally friendly behaviour of Swiss consumers, and found that their motivations towards more sustainable food consumption is variable according to some sociodemographic and personality factors. These studies confirm that understanding the determinants of sustainable food choices from the perspective of consumers is of the utmost importance. However, those studies are limited in scope, specifically because they apply to a single country. There is little information on how consumers shape their behaviours having in mind sustainability issues on a large scale. Hence the importance of the present research, which was conducted simultaneously in different countries, and reports data obtained though the same questionnaire applied in 13 countries. The geographical coverage is a certain advantage, since it includes countries spread all over the European continent, but also in the American continent (Brazil and Argentina in South America and United States in North America). The purpose of this study was to see the influence of sociodemographic variables (age, sex, education, country, living environment, marital status and professional area) on the food choices related to environmental aspects and sustainability of the food chain.

\section{Materials and Methods}

This work intended to investigate in what way people modulate their food choices according to sustainability issues.

This was an observational study carried out by means of a questionnaire survey on 13 different countries. The questionnaire was prepared in the ambit of the EATMOT 
project [20]. The objective behind the development of this project was to perform a study about the different psychic and social motivations that determine people's eating patterns, either in relation to their choices or eating habits. Hence, the EATMOT project intended to investigate the drivers of food choice according to six dimensions: health motivations; economic factors; emotional aspects; cultural influences; marketing and commercials; environmental concerns. Hence, to understand the "drivers of food choice", i.e., to perceive "which factors influence people's decision processes when choosing a food to consume", an investigation was carried out by means of a questionnaire survey. In a previous work by Ferrão et al. [20], the whole process of the construction and validation of the questionnaire (either linguistic or statistic) was thoroughly described. The application of the questionnaire in the different countries involved a previous back translation process, to ensure correctness of the transposition into the native languages in all participating countries.

From the EATMOT questionnaire some questions intended to measure in what extent the participants considered sustainability when choosing what to eat, and these are addressed in the present work:

1. I avoid foods with genetically modified organisms;

2. I buy fresh vegetables to cook myself more often than frozen;

3. I choose the foods I eat because it fits the season;

4. It is important to me that the food I eat is prepared/packed in an environmentally friendly way;

5. When I cook, I have in mind the quantities to avoid food waste;

6. It is important to me that the food I eat comes from my own country;

7. I prefer to eat food that has been produced in a way that animals' rights have been respected;

8. I choose foods that have been produced in countries that do not violate Human's rights;

9. I avoid going to restaurants that do not have a recovery policy of food surplus;

10. I prefer to buy foods that comply with policies of minimal usage of packaging.

The participants responded each of these questions expressing their accordance on a 5-point scale (1-totally disagree, 2-disagree, 3-no opinion, 4-agree and 5-totally agree). The questionnaire was approved by the Ethical Committee (Reference $n^{\circ} 04 / 2017$ ) before application. A non-probabilistic convenience sample with 10,067 adult participants from the following 13 countries was used: Argentina, Brazil, Croatia, Greece, Hungary, Latvia, Lithuania, Poland, Portugal, Romania, Serbia, Slovenia and United States.

The survey was conducted between September 2017 and June 2018. The data were collected through online platforms and also by personal interview, in the different countries. The participation was voluntary after giving informed consent. Ethical principles were strictly obeyed when preparing the questionnaire and while collecting and treating the data, that were kept confidential. From the surveyed people, only a very small responses were rejected (less than 1\%) during the validation process. Reasons for this exclusion might include inappropriate filling and/or high number of not answered questions, or missing sociodemographic information, which made it impossible to interpret the results in light of the sociodemographic characteristics.

The variable age of the participants was classified into categories according to: young adults (aged between 18 and 30 years), middle-aged adults (between 31 and 50 years), senior adults (between 51 and 65 years) and elderly (aged 66 years or over).

For the exploratory analysis of the data basic descriptive statistical tools were used, such as frequencies. The crosstabs and the chi square test were used to access the relations between some of the categorical variables under study. Moreover, the Cramer's V coefficient was used to analyse the strength of the significant relations found between some of the variables at study. This coefficient ranges from 0 to 1 and can be interpret as follows: $\mathrm{V} \approx 0.1$ the association is considered weak, $\mathrm{V} \approx 0.3$ the association is moderate and $\mathrm{V} \approx 0.5$ or over, the association is strong [21].

To treat the data, the results obtained for the 10 questions were used to calculate a mean value for each of the participants. This new variable consisted of real numbers 
varying from 1 to 5 , and their interpretation was made according to the following defined scale:

- $\quad$ value $\in[1.0,3.0]$ —food choices not influenced by sustainability issues;

- $\quad$ value $\in[3.0,5.0]$ —food choices influenced by sustainability issues.

The variable accounting for the Influence of Sustainability issues on the Food Choices (ISFC) was submitted to a tree classification analysis for evaluation of the relative importance of each of the possible influential variables considered: sex, age class, marital status, level of education, professional area, country and living environment. The analysis followed the CRT (Classification and Regression Trees) algorithm with cross validation and with minimum change in improvement of 0.005 , considering a limit of 5 levels and the minimum number of cases for parent or child nodes equal to 100 and 50 , respectively.

To establish some possible constructs in terms of sustainability in the food chain, the items of the questionnaire were categorized in terms of their contribution to some variables established, namely: Preservation of Biodiversity (PB), Respect for Life (RL), Save Natural Resources (SNR), Save Energy (SE), Reduce Industrial Pollution (RIP) and Minimal Packaging (MP), which in turn allowed for the identification of two dimensions of sustainability: Preservation of Natural Environments (PNE) and Minimize Industrial Impact (MII). All these variables were subject to a reliability analysis by means of Cronbach's alpha $(\alpha)$. This coefficient measures the internal consistency of the data and the higher the value, i.e., the closest to 1 , the better the internal consistency. Although some different classification scales can be found for alpha, most agree that values over nine are excellent, between eight and nine are good, and over six are acceptable [22-24]. For all the variables and constructs established, the values for each participant were calculated as an average of all items included in each of them, and therefore the values obtained were real numbers between 1 and 5 .

A discriminant function analysis was also performed for the categorical variable country and the six ratio variables defined: PB, RL, SNR, SE, RIP, MP. For this, the stepwise method with Mahalanobis distance was used, and the criteria was the probability of $\mathrm{F}$. The assumptions were verified through the test of equality of covariance matrices (Box's M test) and the test of equality of group means was also performed.

The data were processed using the SPSS program, version 26 from IBM, Inc, and the level of significance used was $5 \%$.

\section{Results and Discussion}

\subsection{Sample Characterization}

Table 1 shows the sociodemographic characterization of the sample. Given that for some of the socio-demographic variables some categories were underrepresented, some of the categories were collapsed in order to make results more stable. The sample consisted of 10,067 participants, distributed by age classes as: 4988 young adults (18-30 years), 3495 middle-aged adults (31-50 years), 1355 senior adults (51-65 years) and a lower participation of elderly people (66 years or over), only 229 . Therefore, these two groups were joined into one class accounting for the people aged 51 years or over, as indicated in Table 1.

Regarding the sex distribution, the participants were mostly women, 7117 participants, and 2950 were men.

Concerning education, most had a university degree (6150), followed by secondary school (3710), with just a few with lower education (207 participants with primary school). Again, the two latest categories were merged into one, accounting for participants with education up to secondary school.

The participants were from all the 13 countries, as indicated in Table 1, but Croatia, Portugal and Slovenia contributed with more participants, $15.3 \%, 13.1 \%$ and $10.8 \%$, respectively. Most participants lived in urban environments (7020) or suburban (1663) and only 1384 participants lived in rural environments. Additionally, in this case the categories suburban and rural were merged (Table 1). Concerning marital status, 4756 participants 
were single, 4804 were married or living together, 499 were divorced or separated and 188 were widowed. To this matter, the categories single, divorced and widowed were grouped into one unique category, accounting for people who do not have a partner, as opposed to the participants who has a life partner.

Table 1. Sample characterization $(n=10,067)$.

\begin{tabular}{|c|c|c|c|c|c|}
\hline Variable/Group & $n$ & $\%$ & Variable/Group & $n$ & $\%$ \\
\hline Age group & & & Living environmen & & \\
\hline Young Adults & 4988 & 49.5 & Urban & 7020 & 69.7 \\
\hline Middle-aged Adults & 3495 & 34.7 & Suburban/Rural & 3047 & 30.3 \\
\hline Senior Adults/Elderly & 1584 & 15.8 & Country & & \\
\hline Sex & & & Argentina & 522 & 5.2 \\
\hline Women & 7117 & 70.7 & Brazil & 665 & 6.6 \\
\hline Men & 2950 & 29.3 & Croatia & 1538 & 15.3 \\
\hline Education & & & Greece & 498 & 4.9 \\
\hline Up to secondary School & 3917 & 38.9 & Hungary & 500 & 5.0 \\
\hline University & 6150 & 61.1 & Latvia & 636 & 6.3 \\
\hline Marital status & & & Lithuania & 507 & 5.0 \\
\hline Married & 4804 & 47.7 & Poland & 586 & 5.8 \\
\hline Single/Divorced/Widowed & 5443 & 52.3 & Portugal & 1314 & 13.1 \\
\hline Professional area & & & Romania & 821 & 8.2 \\
\hline Nutrition & 937 & 9.3 & Serbia & 498 & 4.9 \\
\hline Food & 1048 & 10.4 & Slovenia & 1092 & 10.8 \\
\hline Agriculture & 356 & 3.5 & United States & 890 & 8.9 \\
\hline Sport & 349 & 3.5 & & & \\
\hline Psychology & 438 & 4.4 & & & \\
\hline Health & 1823 & 18.1 & & & \\
\hline Others & 5116 & 50.8 & & & \\
\hline
\end{tabular}

Finally, the professional area was also asked given the interest it might have as a potential influencing variable for the food choices. For the provided areas, it was found that $18.1 \%$ had a profession or studies related with health, $10.4 \%$ for food, $9.3 \%$ for nutrition, and them minor percentages for psychology $(4.4 \%)$, sport $(3.5 \%)$ or agriculture $(3.5 \%)$. The remaining participants $(50.8 \%)$ were from other areas.

\subsection{Food Choices Related with Environmental and Sustainability Issues}

Figure 1 shows the frequencies of response obtained for the questions that were investigated in the present work, and which relate to food choices in relation with some aspects linked to sustainability of the food chain. Regarding the genetically modified organisms (GMO), nearly half of the participants avoid them (27.6\% agree with the statement and $19.4 \%$ strongly agree). The problem of GMOs is not consensual even among the scientific committee, because some argue that they compromise ecosystems biodiversity but others state that they allow better production and the need to use less chemical products, such as pesticides [25-27].

Most participants prefer to buy fresh vegetables $(40.6+33.5=74.1 \%)$ instead of frozen (Q2), which is beneficial given the intensive energy expenditure associated with the storage and transportation of frozen foods, and knowing that most of the energy consumed on a world basis is still from fossil sources and emitting greenhouse gases (GHG) $[28,29]$.

The preference for foods proper of the season (Q3) is also strong among the participants $(42.5+13.5=56.0 \%)$, also contributing for a more sustainable food chain, because, again, the need to store foods all year round is very energy-demanding [30]. 


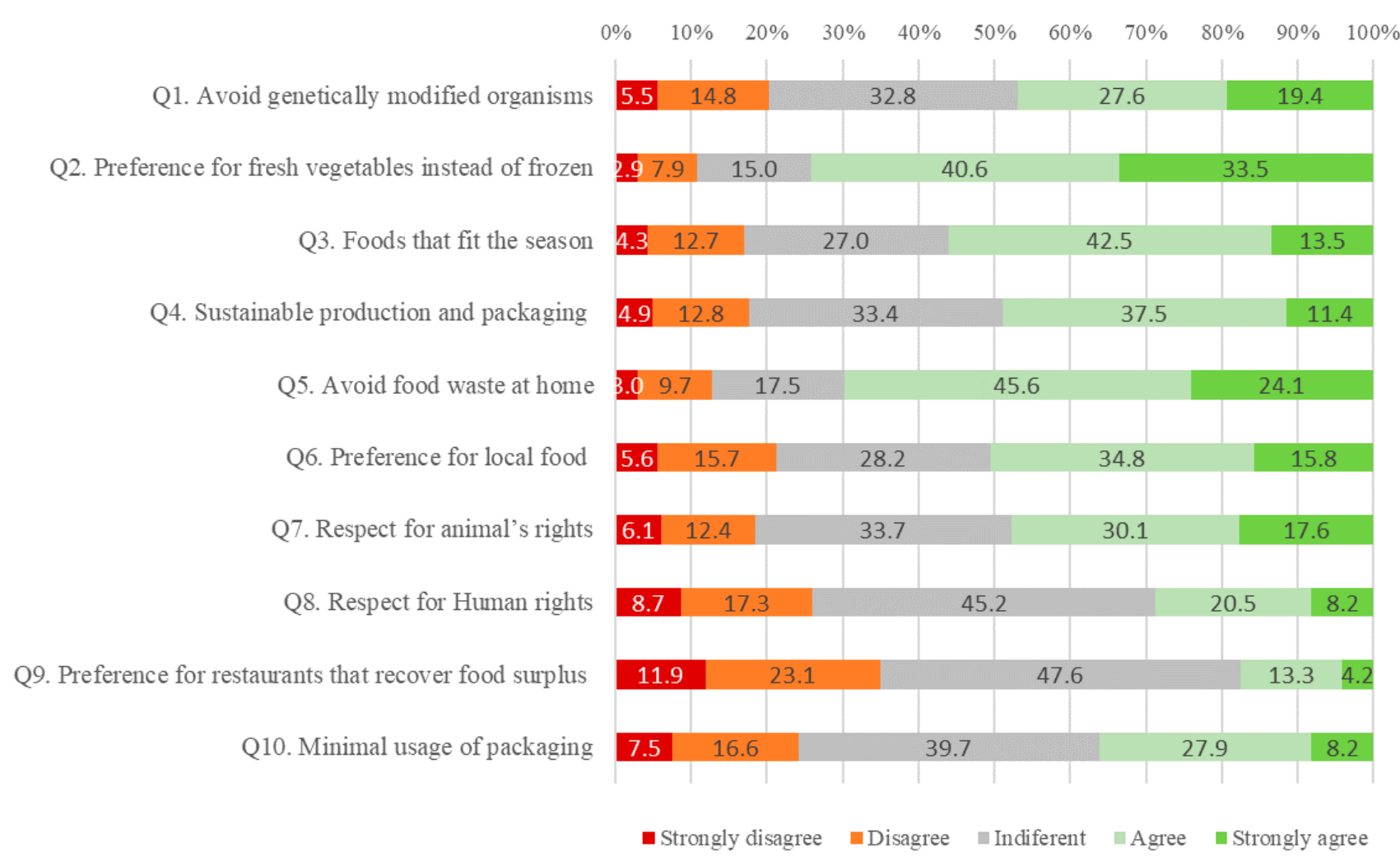

Figure 1. Frequency of response for the 10 questions about sustainable food choices.

Concerning the preference for foods that that originate from sustainable processing systems and packaging $(\mathrm{Q} 4)$, also a great majority of the participants agree with this $(37.5 \%)$ and some totally agree $(11.4 \%)$, indicating that people are influenced by these aspects when buying their food. At the global level, the challenges of the food sector to ensure overall food security to a world growing population are enormous, furthermore in a context of climate change and ecosystems' degradation [31]. Hence it is imperative to establish policies that drive consumers to shift to more sustainable and less resource-intensive food choices. Aschemann-Witzel and Zielke [31] reported that price constitutes the most relevant barrier for consumers to purchase organic foods. However, the income is only a partial explanatory factor because also other psychographic factors affect the decision processes. The same researchers [31] also found that consumers are willing to pay a premium of $30 \%$, on average, for organic foods as compared with their conventional counterparts.

With regards to the food packaging materials, included in question $\mathrm{Q} 4$, these are under social scrutiny because the single use plastics, so intensely used in food packaging, are highly harmful for the environment if not carefully disposed for recycling [32-34]. On a related question $(\mathrm{Q} 10)$ not many participants indicated driving their food choices according to the minimal use of packaging $(27.9+8.2=36.1 \%)$. These results combined show that although participants want to buy foods produced and packed in sustainable ways, they do not want to let go of the food package. However, this is in accordance with modern trends to replace traditional synthetic plastic packaging materials by alternative biodegradable materials produced from organic sources, that minimizes environmental impact for their production and also on disposal [35-37].

The results obtained for question Q5, about avoiding or minimizing food waste when preparing or consuming foods at home, indicated that the participants worry about these aspects $(45.6+24.1=69.7 \%)$. On the other hand, when food is wasted in restaurants, people do not seem to care and only $17.5 \%(13.3+4.2 \%)$ admit prefer going to restaurants that have a food surplus recovery police (Q9). Food remains and losses waste an important amount of natural resources: $25 \%$ of all water used annually in agriculture and $23 \%$ of global cropland; 
while generating about $8 \%$ of annual global GHG emissions [38-40]. Additionally, many of the discarded food products are in fact still edible and in a good state for consumption, and therefore their utilization for social purposes is of the utmost importance [41-43].

The preference for local food (Q6), i.e., foods that have been produced in the same country where they are consumed, also contributes for a smaller environmental impact, allied to transportation and storage. This aspect seems to condition the food choice for about half of the participants $(34.8+15.8=50.6 \%)$. Local foods have a social dimension, contributing for the development of local communities and the establishment of local production systems may also contribute to a more efficient use of locally available renewable resources [44-47].

Other aspects that relate not only with sustainability but also with some social issues relate with the respect for animal and human rights. The results of this study revealed that $47.7 \%(30.1+17.6)$ have the respect for animal rights as a factor conditioning their food choices (Q7) while a lower number, $28.7 \%(20.5+8.2)$, worry about human rights (Q8). In some countries the awareness for the wellbeing of animals is very much discussed, and this alerts consumers, but the problem of human rights is less discussed, maybe because some people feel that it might happen in some parts of the globe that are more distant and so they do not feel it so intensively. Zander and Hamm [48] discuss the relevance of ethical attributes for the marketing of organic foods, including not only environmental aspects of organic food, but also aspects linked with animal welfare. Many research works reported that animal welfare influences people's food decisions [49], particularly when consuming eggs [50], milk [51] or meat [52,53].

\subsection{Influence of Sociodemographic Variables on Sustainable Food Choices}

As described earlier, the results obtained for the 10 questions allowed to calculate a mean value for each of the participants, and this was then used to classify them into people whose food choices are or are not influenced by sustainability issues. Table 2 shows the cross tabulation between the influence of sustainability issues on the food choices (variable ISFC) with the sociodemographic variables considered: age, sex, marital status, level of education and professional area. In the table are also presented the values of significance of the chi-square tests and the value of the Cramer's coefficient, which allows to verify the strength of the association between variables.

The results in Table 2 further reveal that people with a university degree are more prone to make food choices influenced by sustainability issues $(74.8 \%)$ as compared with people who completed secondary school or primary school (68.3\%). The work by Panzone et al. [55] examined to what extent the socio-demographic characteristics, either implicit or explicit attitudes towards the environment, can influence consumer behaviour towards more sustainable choices. They found that the level of education has a major role in predicting sustainable consumption, this influence also being related with the explicit level of concern for climate change. Finally, it was also observed that the professional area influenced how people made food choices, i.e., if they were influenced by sustainability issues. So, a higher percentage of people linked with agriculture $(75.3 \%)$ are concerned with sustainability as compared with other areas. The sector of agriculture is particularly important for this matter, since agriculture can be one of the great contributors for environmental impacts of the food chain, particularly in what concerns the intensive agriculture and animal production [56-58]. Alternatively, more sustainable production methods have been gaining importance in past decades, such as organic farming $[59,60]$. Nevertheless, other professional areas also presented high percentages of people whose foods choices are influenced by sustainability issues: food $(72.5 \%)$, health $(72.0 \%)$, nutrition $(71.5 \%)$ as well as the non-specified areas $(74.0 \%)$. However, participants whose professional area is psychology revealed the lowest concerns with sustainability relating to their food choices (58.4\%) followed by people whose work is related with sports (63.6\%).

The results in Table 2 show that for all the tested influential variables the $p$-value was significant at the level of significance of $5 \%$, which means that there were significant 
differences among groups for each of the sociodemographic variables considered. However, the associations were in general weak, considering the values of coefficient $V$ (lower than 0.2). For the age classes, it was observed that as age increased the people became more influenced by sustainability issues when making their food choices: for young adults $65.2 \%$ were influenced while for people over 51 years old (senior adults and elderly) that percentage increased to $83.8 \%$. Regarding sex, women made food choices more influenced by sustainability issues than men $(75.6 \%$ against $64.3 \%$, respectively). In what concerns marital status, the married participants were more influenced by sustainability issues (78.1\%) when compared with single, divorced or widowed participants (64.3\%). Individual characteristics help shaping the mental structure that drives food choice. Some authors have used the means-end-chain theory, which is an approach based on personal construct psychology, to model the mental links that people construct between the products' characteristics and what they believe are the consequences of their choices and file values [54]. From the perspective of behavioural change, this cognitive structure approach delivers relevant insights to understand food choice determinants.

Table 2. Association between sociodemographic factors and influence of sustainability on the food choices (ISFC).

\begin{tabular}{|c|c|c|c|c|}
\hline Variable/Group & $\begin{array}{c}\text { Not Influenced } \\
(\%)\end{array}$ & $\begin{array}{c}\text { Influenced } \\
(\%)\end{array}$ & $\begin{array}{c}\text { Chi-Square } \\
p \text {-Value }\end{array}$ & $\begin{array}{c}\text { Cramer's } \\
\text { Coefficient, V }\end{array}$ \\
\hline Age group & & & \multirow{4}{*}{$<0.0005$} & \multirow{4}{*}{0.164} \\
\hline Young Adults & 34.8 & 65.2 & & \\
\hline Middle-aged Adults & 22.9 & 77.1 & & \\
\hline Senior Adults/Elderly & 16.2 & 83.8 & & \\
\hline \multicolumn{4}{|l|}{ Sex } & \multirow{3}{*}{0.114} \\
\hline Women & 24.4 & 75.6 & \multirow[t]{2}{*}{$<0.0005$} & \\
\hline Men & 35.7 & 64.3 & & \\
\hline \multicolumn{3}{|l|}{ Marital status } & \multirow{3}{*}{$<0.0005$} & \multirow{3}{*}{0.124} \\
\hline Married & 21.9 & 78.1 & & \\
\hline Single/Divorced/Widowed & 33.0 & 67.0 & & \\
\hline \multicolumn{3}{|l|}{ Education } & \multirow{3}{*}{$<0.0005$} & \multirow{3}{*}{0.070} \\
\hline Up to secondary School & 31.7 & 68.3 & & \\
\hline University & 25.2 & 74.8 & & \\
\hline \multicolumn{3}{|l|}{ Professional area } & \multirow{8}{*}{$<0.0005$} & \multirow{8}{*}{0.080} \\
\hline Nutrition & 28.5 & 71.5 & & \\
\hline Food & 27.5 & 72.5 & & \\
\hline Agriculture & 24.7 & 75.3 & & \\
\hline Sport & 36.4 & 63.6 & & \\
\hline Psychology & 41.6 & 58.4 & & \\
\hline Health & 28.0 & 72.0 & & \\
\hline Others & 26.0 & 74.0 & & \\
\hline
\end{tabular}

Meyer-Höfer et al. [61] suggested a typical profile for what they called "convinced sustainable consumers", as being mostly women who understand that their personal purchase decisions actually impact on the sustainable development at global level. Additionally, these women are willing to improve sustainability through their individual consumption behaviour. Finally, they treasure high quality foods and are not significantly influenced by advertisements and offers when they have to decide which product to purchase.

Table 3 presents the associations between influence of sustainability issues in food choices (variable ISFC), according to some geographical variables: living environment and country. The results indicated that there were significant differences between the groups for these two variables, but while for living environment the association was weak, for variable country the association was strong, meaning that country differences are very important. Regarding the variable living environment, people from urban areas make their 
food choices more influenced by sustainability issues $(73.4 \%)$ than others $(69.7 \%$ for people living in suburban or rural areas).

Table 3. Association between geographic factors and influence of sustainability on the food choices (ISFC).

\begin{tabular}{ccccc}
\hline Variable/Group & $\begin{array}{c}\text { Not Influenced } \\
(\mathbf{\%})\end{array}$ & $\begin{array}{c}\text { Influenced } \\
\mathbf{( \% )}\end{array}$ & $\begin{array}{c}\text { Chi-Square } \\
\boldsymbol{p} \text {-Value }\end{array}$ & $\begin{array}{c}\text { Cramer's } \\
\text { Coefficient, V }\end{array}$ \\
\hline Living environment & & 73.4 & $<0.0005$ & 0.038 \\
Urban & 26.6 & 69.7 & \\
Suburban/Rural & 30.3 & 65.9 & \\
Country & & 71.6 & \\
Argentina & 34.1 & 70.3 & \\
Brazil & 28.4 & 71.3 & \\
Croatia & 29.7 & 56.2 & \\
Greece & 28.7 & 67.5 & \\
Hungary & 43.8 & 70.0 & \\
Latvia & 32.5 & 75.6 & \\
Lithuania & 30.0 & 92.3 & \\
Poland & 24.4 & 80.3 & \\
Portugal & 7.7 & 67.9 & \\
Romania & 19.7 & 79.8 & \\
Serbia & 32.1 & 48.3 & \\
Slovenia & 20.2 & 51.7 & & \\
United States & & & \\
\hline
\end{tabular}

Cultural factors act as drivers of food choice and country differences encompass, not only the dimension of social and cultural influences, but also the dimension of political actions and measures aimed at provoking a shift towards more sustainable options [62,63]. Cuevas et al. [64] developed a framework of Gastronomic Systems Research (GSR) aimed at understanding consumer food choices according to specific cultural backgrounds, on a context of urban high-income consumers. In the pursuit to understand the motivations of food choice, a holistic approach can be considered to identify knowledge gaps and target specific intervention points along the food supply chain. An interdisciplinarity must be sought also to address the consumers' cultural backgrounds and societal features $[65,66]$.

\subsection{Tree Classification Analysis}

The variable accounting for the influence of sustainability on the food choices (ISFC) was then submitted to a tree classification, according to the influence of the seven variables tested. The tree resulting from the application of the CRT algorithm to the problem in question can be seen in Figure 2 (in a reduced version) and Figure S1 (detailed tree-available for download as a high-resolution image). The obtained tree had 5 levels and 51 nodes, from which 26 were terminal. The risk estimate was 0.265 for resubstitution and 0.272 for cross-validation, with standard errors of 0.004 in both cases. The results showed that the first discriminant variable was country, separating the initial sample into two different groups: Group A including four countries (Portugal, Poland, Romania and Slovenia), and Group B for the other nine countries (Argentina, Croatia, Greece, Latvia, Lithuania, United States, Serbia, Hungary and Brazil). Interestingly, in both groups the following discriminant variable was again country, separating into A1 (Portugal) and A2 (Poland, Romania, Slovenia), and also B1 (United States, Hungary) and B2 (Argentina, Croatia, Greece, Latvia, Lithuania, Serbia and Brazil) (Figure S1). This confirms the strong influence of country as a differentiating factor for the influence of sustainability on food choices. The following level shows that in all cases age class was the discriminant variable in all countries. However, in the 3rd level of the tree classification a slight variability of discriminating factors was observed, although in most of the cases (six out of seven) the discrimination was made according to sex. For the young adults from Portugal, the 
level 4 discriminant was professional area originating two distinctive groups, one of them including areas such as food, nutrition and health.

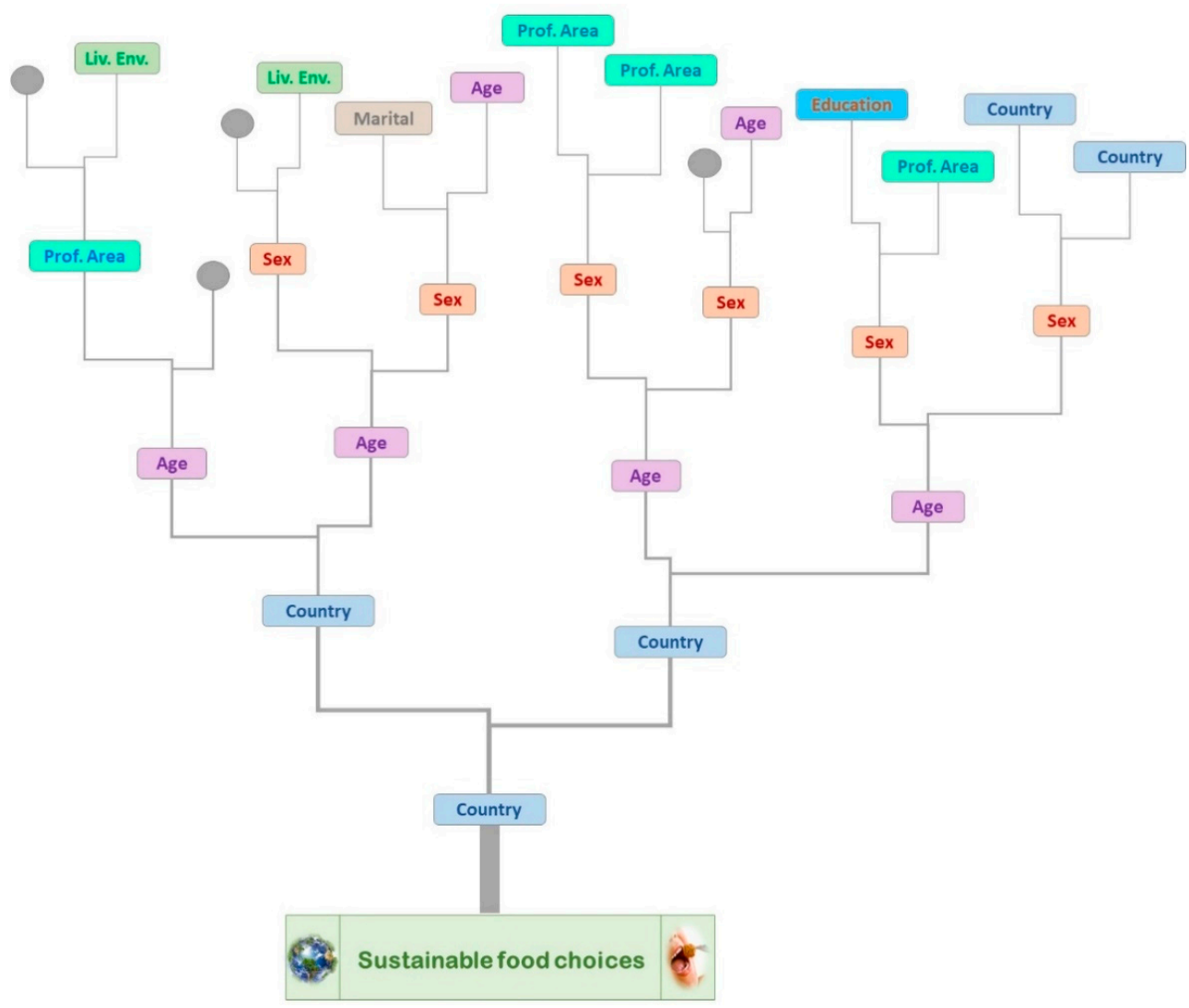

Figure 2. Simplified version of the tree classification for influence of sociodemographic variables on sustainable food choices. (A more complete version is available as supplementary material—Figure S1).

At node zero, i.e., for all the sample, the percentage of people that make food choices influenced by sustainability issues was $72.3 \%$. In the second level, i.e., separations according to countries, for Portugal, Poland, Romania and Slovenia that percentage was the highest, $83.6 \%$, while for the group of the other countries the percentage was considerably lower, $65.4 \%$. The behaviour of consumers towards sustainability is much different depending on the country, which might be explained by differences in culture, ways of life, conscientiousness and political measures implemented to educate consumers towards more responsible choices, not only regarding the food they consume but also other actions that have impact on global sustainability. Sometimes sustainable options look more expensive at a first glance, because these options are meant to have additional non-financial implications, that are thought on a long-term basis rather than immediate profit.

\subsection{Dimensions of Sustainability in the Food Chain}

Figure 3 resumes the reliability analysis conducted to the variables created to establish some possible constructs in terms of sustainability in the food chain, according to the contributions of the questionnaire items. The results show that for most of the variables $(\mathrm{PB}, \mathrm{SNR}$, SE and RIP) the values of alpha were too low, under the limit for acceptable $(\alpha<0.6)$, just with exceptions for variables RL with $\alpha=0.700$ and MP with $\alpha=0.686$. However, when the variables were grouped into wider constructs, the internal reliability increased considerably so that both constructs have acceptable values of alpha: $\alpha=0.712$ for PNE and $\alpha=0.677$ for MII. According to some authors values over 0.6 are acceptable [22-24], although values equal to 0.7 or higher would be desirable [22,23]. The internal consistency of the whole factor Dimensions of Sustainability in the Food Chain (DSFC) was good $(\alpha=0.805)$ [22-24]. 
Moreover, in all reliability tests made, the removal of any of the variables did not increase alpha, and thus, it was concluded that all items should be included in the definition of the variables and constructs.

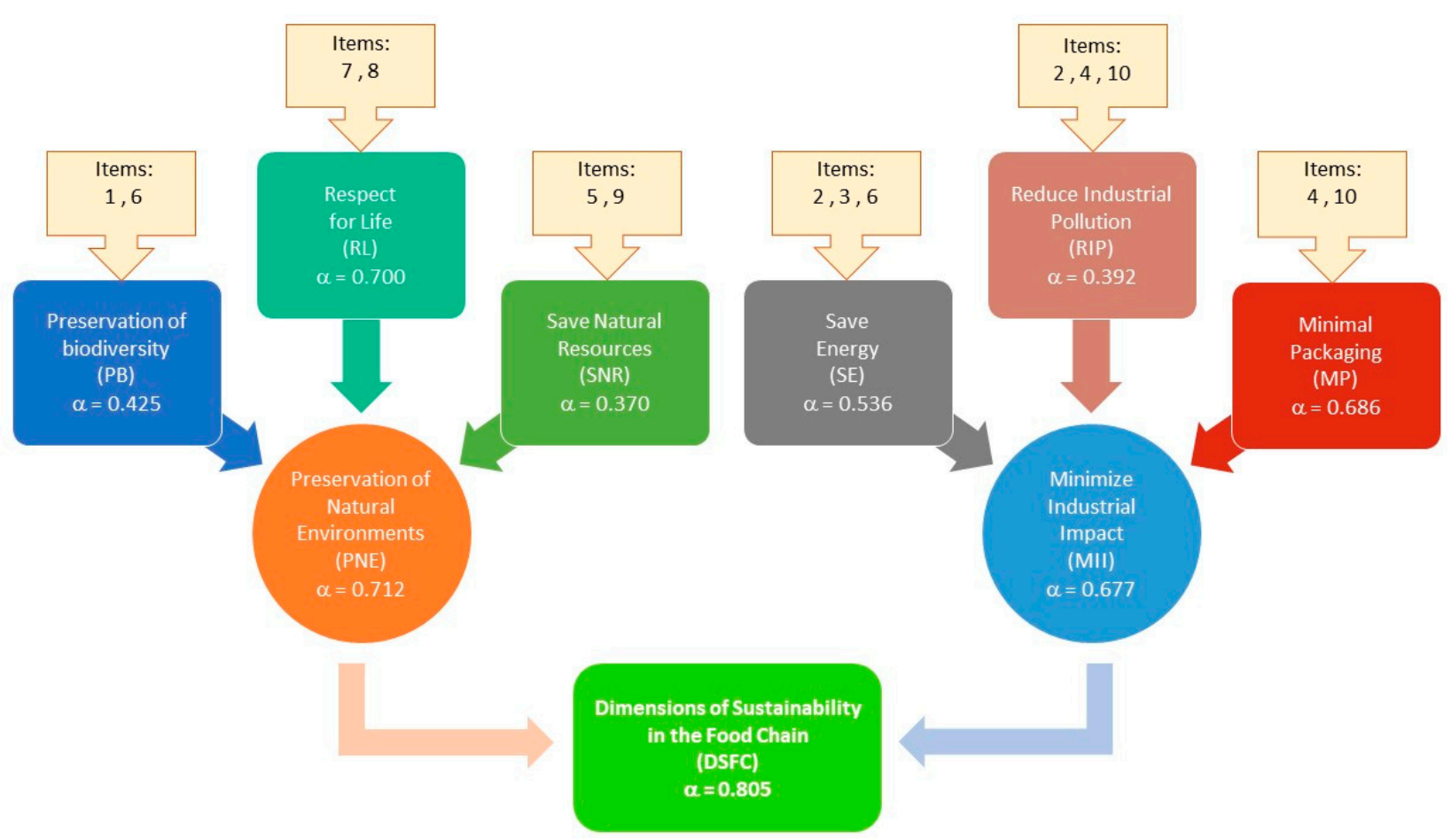

Figure 3. Reliability of the variables established for dimensions of sustainability in the food chain.

The preservation of natural environments allied to the minimization of industrial impact are two key points that contribute to achieve the SDGs of the United Nations by 2030 [2]. Aspects such as preservation of biodiversity, save natural resources, save energy, reduce industrial pollution, respect for life and minimal packaging are at the centre of attention both from the point of view of consumers and also producers. The establishment of short chains for food supply has been emerging in recent years, due not only to the increasing concerns with the environment, but also because more attention is focused on aspects such as food safety and human health, not forgetting animal welfare or ecological and sustainability issues. The short food supply chains are linked with ecological, environmental and social dimensions, since they rely much on local suppliers as well as on the characteristics of local buyers while minimizing transportation and storage, thus allowing to save a considerable amount of energy [39,67,68]. Additionally, these practices are also allied to more traditional processing, thus eventually reducing the impacts of the food industries, also due to the use of lower amounts of packaging [69]. The food supply chains are responsible for a considerable amount of pollution cause by packaging materials. Most food providers of food services use durable plastic bags and meal boxes to easily transport foods, owing to the low cost of those materials allied to their convenience and functional advantages when compared with other materials such as glass or tinplates [70,71]. The industrialized food products also follow a similar pattern, due to the need to protect foods along the supply chain, from the production unit to the table of the consumers. Hence, food packaging, by representing the largest demand for plastic packaging, is rather important in the management of plastic waste [35].

\subsection{Discriminant Function Analysis}

As the results from the tree classification analysis showed that the most discriminating variable for the sustainable food choices was country (both in the first and the second levels) a discriminant function analysis was performed for country as dependent variable and 
considering as independent variables the six defined for the sustainability in the food chain: PB, RL, SNR, SE, RIP and MP. The results showed that Wilks's lambda was significant by the $\mathrm{F}$ test for all independent variables ( $p<0.0005$ in all cases), and variables with smaller value of Wilks's lambda were Se and ROR, thus being those more important for the discriminant analysis. The correlation matrix showed that the highest correlations between predictors were 0.892 (correlation between MP and RIP) and 0.643 (between RIP and SE). Table 4 shows the results of discriminant function analysis, that produced six functions. The first function, with the highest eigenvalue, explains $36.0 \%$ of variance, followed by F2, explaining $30.4 \%$ of variance and so on, and in global, all the six functions explain $100 \%$ of the variance. The results also indicate that the six functions are significant ( $p$-value $<0.0005$ in all cases). The value of Wilks' lambda is lower for F1, so this has the best discriminant ability. The canonical correlation coefficients measure the association between the functions and the variable country, and in this case the highest was for function F1.

Table 4. Results of discriminant function analysis.

\begin{tabular}{cccccc}
\hline Function & Eigenvalue & $\begin{array}{c}\text { \% Variance } \\
\text { Explained }\end{array}$ & $\begin{array}{c}\text { Canonical } \\
\text { Correlation }\end{array}$ & $\begin{array}{c}\text { Wilks' } \\
\text { Lambda }\end{array}$ & $p$-Value \\
\hline F1 & 0.169 & 36.0 & 0.380 & 0.643 & $<0.0005$ \\
F2 & 0.142 & 30.4 & 0.353 & 0.751 & $<0.0005$ \\
F3 & 0.067 & 14.2 & 0.250 & 0.858 & $<0.0005$ \\
F4 & 0.044 & 9.4 & 0.206 & 0.915 & $<0.0005$ \\
F5 & 0.031 & 6.6 & 0.173 & 0.955 & $<0.0005$ \\
F6 & 0.016 & 3.4 & 0.124 & 0.985 & $<0.0005$ \\
\hline
\end{tabular}

The results of the structure matrix (Table 5) show that coefficients with large absolute values correspond to variables with greater discriminating ability. In this case, the greater discriminant ability in function F1 is provided by variable RIP (0.751), in F2 is variable SE (0.901), in F3 and F4 is RL (0.562 and 0.688, respectively), in F5 is variable SNR (0.497) and in F6 is MP (0.561). Variables with loadings lower than 0.3 (absolute value) were excluded from the model.

Table 5. Structure matrix.

\begin{tabular}{ccccccc}
\hline & \multicolumn{7}{c}{ Functions } \\
\hline Variables $^{1}$ & F1 & F2 & F3 & F4 & F5 & F6 \\
\hline RIP & $0.751^{*}$ & 0.384 & 0.113 & 0.367 & -0.111 & 0.358 \\
SNR & $0.716^{*}$ & 0.287 & -0.154 & 0.280 & 0.497 & -0.235 \\
MP & $0.685^{*}$ & 0.226 & 0.180 & 0.264 & 0.250 & 0.561 \\
SE & 0.311 & $0.901^{*}$ & 0.212 & 0.126 & -0.161 & -0.069 \\
PB & -0.110 & $0.771^{*}$ & -0.159 & 0.494 & 0.261 & 0.235 \\
RL & 0.324 & 0.097 & 0.562 & $0.688^{*}$ & 0.309 & -0.013 \\
\hline
\end{tabular}

${ }^{1}$ RIP = Reduce Industrial Pollution, SNR = Save Natural Resources, MP = Minimal Packaging, SE = Save Energy, $\mathrm{PB}=$ Preservation of Biodiversity, $\mathrm{RL}=$ Respect for Life. ${ }^{*}$ Largest absolute correlation between each variable and any discriminant function.

The results indicate that the aspects related with saving energy and natural resources allied to the reduction of industrial pollution and the care for preservation of biodiversity are strong factors that drive the food choices, in the countries included in this study, towards sustainable food chains. As previously amply discussed, these aspects are important to change the food supply chains into more environmentally friendly ones.

Figure 4 shows the distribution of the different county groups according to the discriminant functions. The huge cloud of points results from the very high number of participants representing each of the countries, but the dispersion is somewhat limited. Still, the centres representing each of the countries show some differences, such as that United States is quite alone, and so is Portugal, although on an opposite side of the map. Countries such as 
Argentina and Brazil are quite close and most European countries form a cohesive group, just with Greece standing out. These results highlight, on one side, the importance of geographical location on the shaping of consumer behaviour, and on the other side, the role of common political measures to influence people's food choices. The countries in the European Union have some common policies that might explain why the European citizens tend to similar trends in regards to sustainable food options. The European Union aims to be a leader in what concerns driving the world towards sustainability. The proposal from 2018 of the European Commission for Horizon Europe specifically mentions the Sustainable Development Goals of the United Nations Agenda 2030 as the pivotal focus of the programme [72,73]. There is relevant confirmation that specific social norms linked to food consumption have a major effect on people's food choices. On the other hand, the globalization of food supply chains has increased the availability and variety of foods, becoming eventually less sustainable, owing to long distances travelled across the globe and/or being available throughout the entire year and not only in the production season [74-76].

The model construction was based on the discriminant function coefficients, and resulted in the following equations:

$$
\begin{gathered}
F 1=-3.277+0.961 \times R I P+0.789 \times S N R+0.081 \times M P+0.078 \times S E-0.216 \times R L \\
F 2=-4.110-0.780 \times R I P+1.400 \times S E+0.415 \times P B \\
F 3=-0.370+1.009 \times R L \\
F 4=-2.588+2.460 \times R I P+0.951 \times P B+0.865 \times R L \\
F 5=-0.318+0.870 \times S N R+0.114 \times R L \\
F 6=0.297-0.122 \times R I P+1.528 \times M P
\end{gathered}
$$

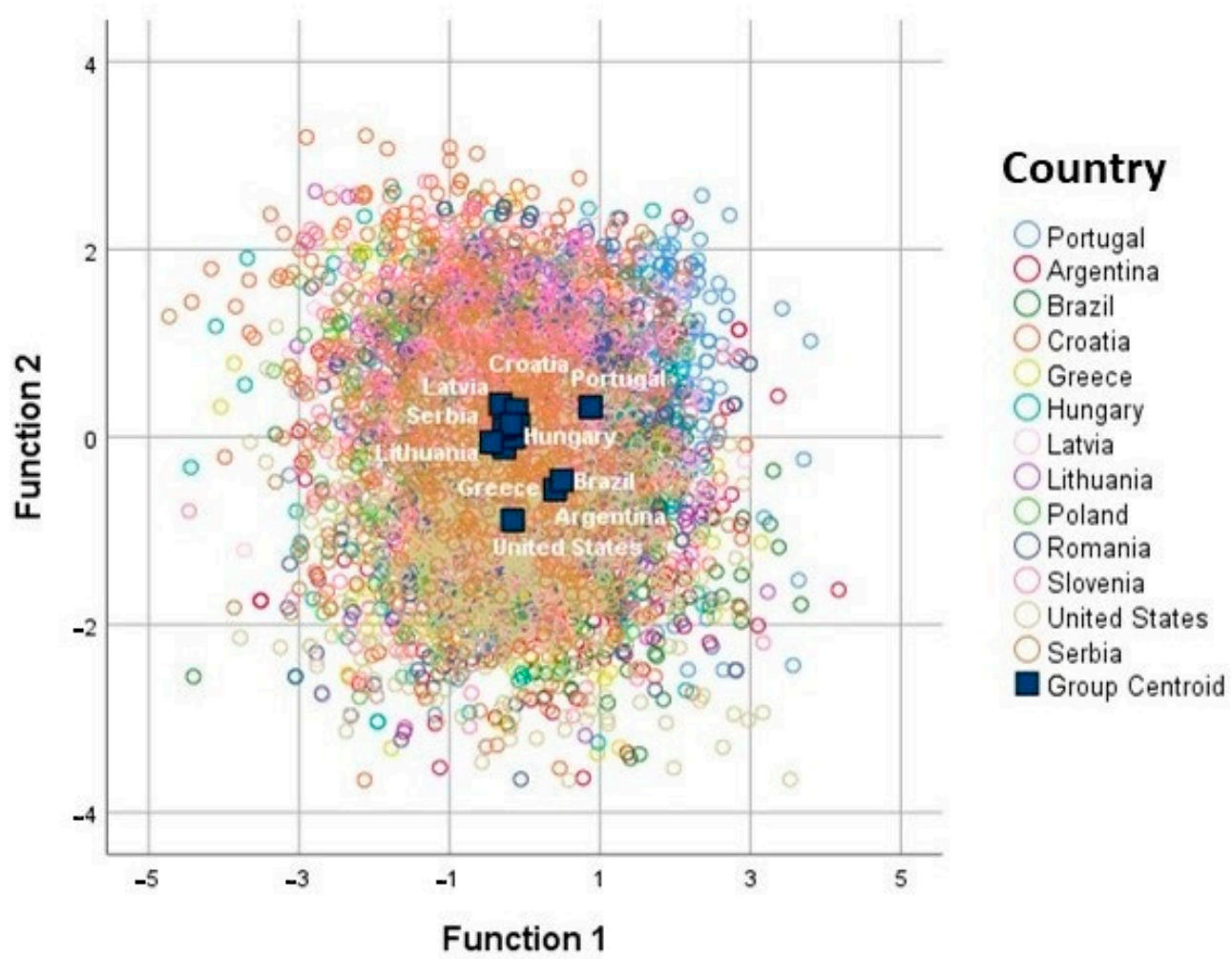

Figure 4. Discriminant functions for the 13 countries of the study. 


\section{Conclusions}

This work allowed us to conclude that most participants in this survey tend to prefer fresh local foods from the season, which minimizes storage and transportation. People in the countries included in the study tend to minimize food waste at home, but the awareness for the waste at restaurants still needs to be increased. The consumers opt for foods that have been produced and packed in sustainable ways but do not want to get rid of packaging, which leads to the need to replace harmful plastic materials by sustainable options, such as natural biodegradable films.

Additionally, it was concluded that there were significant differences between groups for all sociodemographic variables tested (age, sex, marital status, education, professional area, living environment and country), but the association was high only for variable country, being weak in all other cases. Finally, tree classification analysis allowed us to identify the relative importance of the influential variables on the sustainable food choices, with country being the discriminant variable on the first and second levels, followed by age and sex. The items were used to define constructs associated with the preservation of natural environments and minimization of industrial impacts, validated though internal reliability analysis.

Some limitations of this study can be pointed out, like the use of a convenience sample with non-homogeneous groups' constitution, namely lower representativeness of less educated people, of men and of older people. Additionally, the recruitment in the different countries involves was not equal, with higher participation in some countries. Finally, the choice of the participating countries followed also a convenience criterion, being all these included in the EATMOT project. Nevertheless, this study might be very valuable for a number of factors, such as: this study brings some light into how consumers shape their behaviours towards more sustainable food choices on a wide scale; the fact that this study involved many different countries, with a good geographical coverage, makes it possible to better understand the similarities/differences across different cultural groups; the high number of participants in each of the countries makes these results possibly representative of the rest of the population; and the strong statistical reliability of the obtained results are positive indicators that the formulated conclusions are valuable instruments that can be used with a good degree of confidence.

The implications of this study include a starting point to help increase the knowledge about how sustainability aspects influence people making their food choices, and from that to implement measures at local or global scales to help change consumer behaviours towards more sustainable options.

Supplementary Materials: The following are available online at https://www.mdpi.com/2071-105 0/13/5/2869/s1, Figure S1: Full version of the tree classification for influence of sociodemographic variables on sustainable food choices.

Author Contributions: Conceptualization, R.P.F.G.; formal analysis, R.P.F.G.; investigation, E.B., I.D., M.Č.B., M.T., M.L., V.F., I.R., V.S., D.K., M.K., K.I., P.C., M.F. and A.P.C.; project administration, R.P.F.G.; writing—original draft, R.P.F.G.; writing—review and editing, R.P.F.G., E.B., S.G.F., I.D., M.C.B., M.T., M.L., V.F., I.R, P.O., D.K., M.K. and K.I. All authors have read and agreed to the published version of the manuscript.

Funding: This research and the APC was funded by FCT-Foundation for Science and Technology, I.P, within the scope of projects Ref ${ }^{a}$ UIDB/00742/2020 and Ref $f^{a}$ UIDB/00681/2020.

Institutional Review Board Statement: The study was conducted according to the guidelines of the Declaration of Helsinki, and approved by the Ethics Committee of POLYTECHNIC INSTITUTE OF VISEU-SCHOOL OF HEALTH (Reference n ${ }^{\circ}$ 04/2017, from 9 February 2017).

Informed Consent Statement: Informed consent was obtained from all subjects involved in the study.

Data Availability Statement: The data that support this research can be available from the corresponding author upon reasonable request. 
Acknowledgments: This work was prepared in the ambit of the multinational project EATMOT from CI\&DETS Research Centre (Polytechnic Institute of Viseu, Portugal) with reference PROJ/CI\&DETS/ CGD/0012. This work is funded by National Funds through the FCT-Foundation for Science and Technology, I.P, within the scope of projects Ref ${ }^{a}$ UIDB/00742/2020 and $\operatorname{Ref}^{a}$ UIDB/00681/2020. Furthermore, we would like to thank the UICISA: E and CERNAS Research Centres and the Polytechnic Institute of Viseu for their support.

Conflicts of Interest: The authors declare no conflict of interest. The funders had no role in the design of the study; in the collection, analyses, or interpretation of data; in the writing of the manuscript, or in the decision to publish the results.

\section{References}

1. Pohlmann, C.R.; Scavarda, A.J.; Alves, M.B.; Korzenowski, A.L. The Role of the Focal Company in Sustainable Development Goals: A Brazilian Food Poultry Supply Chain Case Study. J. Clean. Prod. 2020, 245, 118798. [CrossRef]

2. UN. Transforming Our World: The 2030 Agenda for Sustainable Development; United Nations: New York, NY, USA, 2015.

3. Krishnan, R.; Agarwal, R.; Bajada, C.; Arshinder, K. Redesigning a Food Supply Chain for Environmental Sustainability-An Analysis of Resource Use and Recovery. J. Clean. Prod. 2020, 242, 118374. [CrossRef]

4. Guiné, R.P.F.; Correia, P.; Coelho, C.; Costa, C.A. The Role of Edible Insects to Mitigate Challenges for Sustainability. Open Agric. 2021, 6, 24-36. [CrossRef]

5. Guiné, R.P.F.; Gaião, D.; Costa, D.V.T.A.; Correia, P.M.R.; Guerra, L.T.; Correia, H.E.; Costa, C.A. Bridges between Family Farming and Organic Farming: A Study Case of the Iberian Peninsula. Open Agric. 2019, 4, 727-736. [CrossRef]

6. Sarkar, D.; Kar, S.K.; Chattopadhyay, A.; Shikha; Rakshit, A.; Tripathi, V.K.; Dubey, P.K.; Abhilash, P.C. Low Input Sustainable Agriculture: A Viable Climate-Smart Option for Boosting Food Production in a Warming World. Ecol. Indic. 2020, 115, 106412. [CrossRef]

7. O'Neill, D.W.; Fanning, A.L.; Lamb, W.F.; Steinberger, J.K. A Good Life for All within Planetary Boundaries. Nat. Sustain. 2018, 1, 88-95. [CrossRef]

8. Dania, W.A.P.; Xing, K.; Amer, Y. Collaboration Behavioural Factors for Sustainable Agri-Food Supply Chains: A Systematic Review. J. Clean. Prod. 2018, 186, 851-864. [CrossRef]

9. Guiné, R.P.F.; Florença, S.G.; Barroca, M.J.; Anjos, O. The Duality of Innovation and Food Development versus Purely Traditional Foods. Trends Food Sci. Technol. 2021, 109, 16-24. [CrossRef]

10. Horvat, A.; Behdani, B.; Fogliano, V.; Luning, P.A. A Systems Approach to Dynamic Performance Assessment in New Food Product Development. Trends Food Sci. Technol. 2019, 91, 330-338. [CrossRef]

11. Li, X.; Chen, X.; Li, B.; Singh, T.; Shi, K. Predictability of Stock Market Returns: New Evidence from Developed and Developing Countries. Glob. Financ. J. 2021, 100624. [CrossRef]

12. Elhoushy, S. Consumers' Sustainable Food Choices: Antecedents and Motivational Imbalance. Int. J. Hosp. Manag. 2020, 89, 102554. [CrossRef]

13. Iris, G.; Abraham, H.; Doron, K. Examination of the Relationship between Dietary Choice and Consumer Preferences for Sustainable Near-Food Products in Israel. J. Clean. Prod. 2018, 197, 1148-1158. [CrossRef]

14. Dowd, K.; Burke, K.J. The Influence of Ethical Values and Food Choice Motivations on Intentions to Purchase Sustainably Sourced Foods. Appetite 2013, 69, 137-144. [CrossRef]

15. Willett, W.; Rockström, J.; Loken, B.; Springmann, M.; Lang, T.; Vermeulen, S.; Garnett, T.; Tilman, D.; DeClerck, F.; Wood, A.; et al. Food in the Anthropocene: The EAT-Lancet Commission on Healthy Diets from Sustainable Food Systems. Lancet 2019, 393, 447-492. [CrossRef]

16. FAO/WHO. Sustainable Healthy Diets: Guiding Principles; Food and Agriculture Organization of the United Nations/World Health Organization: Rome, Italy, 2019.

17. Fardet, A.; Rock, E. How to Protect Both Health and Food System Sustainability? A Holistic 'Global Health'-Based Approach via the 3V Rule Proposal. Public Health Nutr. 2020, 23, 3028-3044. [CrossRef]

18. Feil, A.A.; da Silva, C.C.C.; Sindelar, F.C.W.; Barden, J.E.; Dalmoro, M. Profiles of Sustainable Food Consumption: Consumer Behavior toward Organic Food in Southern Region of Brazil. J. Clean. Prod. 2020, 258, 120690. [CrossRef]

19. Funk, A.; Sütterlin, B.; Siegrist, M. Consumer Segmentation Based on Stated Environmentally-Friendly Behavior in the Food Domain. Sustain. Prod. Consum. 2021, 25, 173-186. [CrossRef]

20. Ferrão, A.C.; Guine, R.P.F.; Correia, P.; Ferreira, M.; Duarte, J.; Lima, J. Development of A Questionnaire To Assess People's Food Choices Determinants. Curr. Nutr. Food Sci. 2019, 15, 281-295. [CrossRef]

21. Witten, R.; Witte, J. Statistics, 9th ed.; Wiley: Hoboken, NJ, USA, 2009.

22. Hair, J.F.H.; Black, W.C.; Babin, B.J.; Anderson, R.E. Multivariate Data Analysis, 7th ed.; Prentice Hall: Upper Saddle River, NJ, USA, 2009; ISBN 978-0-13-813263-7.

23. Maroco, J.; Garcia-Marques, T. Qual a fiabilidade do alfa de Cronbach? Questões antigas e soluções modernas? Laboratório Psicol. 2006, 4, 65-90. [CrossRef]

24. Davis, F.B. Educational Measurements Their Interpretation; Wadsworth Pub. Co: Marceline, MO, USA, 1964. 
25. Palmieri, N.; Simeone, M.; Russo, C.; Perito, M.A. Profiling Young Consumers' Perceptions of GMO Products: A Case Study on Italian Undergraduate Students. Int. J. Gastron. Food. Sci. 2020, 21, 100224. [CrossRef]

26. Russo, C.; Tufi, E. Consumer Behavior Under Conflicting Information Provided by Interested Parties: Implications for Equilibrium in the Market for Credence Goods. Recent Pat. Food Nutr. Agric. 2016, 8, 4-8. [CrossRef] [PubMed]

27. Covino, D. GMOs and the Issue of Coexistence in Italy. Nutr. Food Sci. 2016, 46, 659-671. [CrossRef]

28. Bilgili, M.; Bilirgen, H.; Ozbek, A.; Ekinci, F.; Demirdelen, T. The Role of Hydropower Installations for Sustainable Energy Development in Turkey and the World. Renew. Energy 2018, 126, 755-764. [CrossRef]

29. IEA. Total Primary Energy Supply (TPES) by Source, World 1990-2017; International Energy Agency: Paris, France, 2019.

30. Konstantas, A.; Stamford, L.; Azapagic, A. Economic Sustainability of Food Supply Chains: Life Cycle Costs and Value Added in the Confectionary and Frozen Desserts Sectors. Sci. Total Environ. 2019, 670, 902-914. [CrossRef]

31. Aschemann-Witzel, J.; Zielke, S. Can't Buy Me Green? A Review of Consumer Perceptions of and Behavior Toward the Price of Organic Food. J. Consum. Aff. 2017, 51, 211-251. [CrossRef]

32. Litchfield, S.G.; Schulz, K.G.; Kelaher, B.P. The Influence of Plastic Pollution and Ocean Change on Detrital Decomposition. Mar. Pollut. Bull. 2020, 158, 111354. [CrossRef]

33. Bishop, G.; Styles, D.; Lens, P.N.L. Recycling of European Plastic Is a Pathway for Plastic Debris in the Ocean. Environ. Int. 2020, 142, 105893. [CrossRef]

34. Ferraro, G.; Failler, P. Governing Plastic Pollution in the Oceans: Institutional Challenges and Areas for Action. Environ. Sci. Policy 2020, 112, 453-460. [CrossRef]

35. Dilkes-Hoffman, L.S.; Lane, J.L.; Grant, T.; Pratt, S.; Lant, P.A.; Laycock, B. Environmental Impact of Biodegradable Food Packaging When Considering Food Waste. J. Clean. Prod. 2018, 180, 325-334. [CrossRef]

36. Engel, J.B.; Ambrosi, A.; Tessaro, I.C. Development of Biodegradable Starch-Based Foams Incorporated with Grape Stalks for Food Packaging. Carbohydr. Polym. 2019, 225, 1-10. [CrossRef] [PubMed]

37. Kamdem, D.P.; Shen, Z.; Nabinejad, O.; Shu, Z. Development of Biodegradable Composite Chitosan-Based Films Incorporated with Xylan and Carvacrol for Food Packaging Application. Food Packag. Shelf Life 2019, 21, 100344. [CrossRef]

38. Teigiserova, D.A.; Hamelin, L.; Thomsen, M. Towards Transparent Valorization of Food Surplus, Waste and Loss: Clarifying Definitions, Food Waste Hierarchy, and Role in the Circular Economy. Sci. Total Environ. 2020, 706, 136033. [CrossRef]

39. Searchinger, T.; Waite, R.; Hanson, C.; Ranganathan, J.; Dumas, P.; Matthews, E. Creating a Sustainable Food Future; World Resources Institute: Washington, DC, USA, 2018; ISBN 978-1-56973-953-2.

40. Kummu, M.; Moel, H.; Porkka, M.; Siebert, S.; Olli, V.; Ward, P. Lost Food, Wasted Resources: Global Food Supply Chain Losses and Their Impacts on Freshwater, Cropland, and Fertiliser Use. Sci. Total Environ. 2012, 438C, 477-489. [CrossRef] [PubMed]

41. Midgley, J.L. Anticipatory Practice and the Making of Surplus Food. Geoforum 2019, 99, 181-189. [CrossRef]

42. Nair, D.J.; Rashidi, T.H.; Dixit, V.V. Estimating Surplus Food Supply for Food Rescue and Delivery Operations. Socio-Econ. Plan. Sci. 2017, 57, 73-83. [CrossRef]

43. Papargyropoulou, E.; Lozano, R.; Steinberger, J.K.; Wright, N.; bin Ujang, Z. The Food Waste Hierarchy as a Framework for the Management of Food Surplus and Food Waste. J. Clean. Prod. 2014, 76, 106-115. [CrossRef]

44. Dedeurwaerdere, T.; De Schutter, O.; Hudon, M.; Mathijs, E.; Annaert, B.; Avermaete, T.; Bleeckx, T.; de Callataÿ, C.; De Snijder, P.; Fernández-Wulff, P.; et al. The Governance Features of Social Enterprise and Social Network Activities of Collective Food Buying Groups. Ecol. Econ. 2017, 140, 123-135. [CrossRef]

45. Garrett, J.J. Future Visions: A Sustainable and Healthy Local Food Production System. Rangelands 2016, 38, 42-46. [CrossRef]

46. Hang, M.Y.L.P.; Martinez-Hernandez, E.; Leach, M.; Yang, A. Designing Integrated Local Production Systems: A Study on the Food-Energy-Water Nexus. J. Clean. Prod. 2016, 135, 1065-1084. [CrossRef]

47. Petrescu-Mag, R.M.; Petrescu, D.C.; Reti, K.-O. My Land Is My Food: Exploring Social Function of Large Land Deals Using Food Security-Land Deals Relation in Five Eastern European Countries. Land Use Policy 2019, 82, 729-741. [CrossRef]

48. Zander, K.; Hamm, U. Information Search Behaviour and Its Determinants: The Case of Ethical Attributes of Organic Food. Int. J. Consum. Stud. 2012, 36, 307-316. [CrossRef]

49. Cornish, A.R.; Briley, D.; Wilson, B.J.; Raubenheimer, D.; Schlosberg, D.; McGreevy, P.D. The Price of Good Welfare: Does Informing Consumers about What on-Package Labels Mean for Animal Welfare Influence Their Purchase Intentions? Appetite 2020, 148, 104577. [CrossRef]

50. Cao, Y.J.; Cranfield, J.; Chen, C.; Widowski, T. Heterogeneous Informational and Attitudinal Impacts on Consumer Preferences for Eggs from Welfare Enhanced Cage Systems. Food Policy 2020, 101979. [CrossRef]

51. Jiang, R.; Sharma, C.; Bryant, R.; Mohan, M.S.; Al-Marashdeh, O.; Harrison, R.; Torrico, D.D. Animal Welfare Information Affects Consumers' Hedonic and Emotional Responses towards Milk. Food Res. Int. 2021, 141, 110006. [CrossRef] [PubMed]

52. Estévez-Moreno, L.X.; María, G.A.; Sepúlveda, W.S.; Villarroel, M.; Miranda-de la Lama, G.C. Attitudes of Meat Consumers in Mexico and Spain about Farm Animal Welfare: A Cross-Cultural Study. Meat Sci. 2021, 173, 108377. [CrossRef] [PubMed]

53. García-Gudiño, J.; Blanco-Penedo, I.; Gispert, M.; Brun, A.; Perea, J.; Font-i-Furnols, M. Understanding Consumers' Perceptions towards Iberian Pig Production and Animal Welfare. Meat Sci. 2021, 172, 108317. [CrossRef]

54. Grunert, K.G. Drivers of Food Choice: A Cognitive Structure Approach to the Determinants of Food Choice and Implications for Affecting Behavior Change. Nutrition 2018, 55-56, S4-S5. [CrossRef] 
55. Panzone, L.; Hilton, D.; Sale, L.; Cohen, D. Socio-Demographics, Implicit Attitudes, Explicit Attitudes, and Sustainable Consumption in Supermarket Shopping. J. Econ. Psychol. 2016, 55, 77-95. [CrossRef]

56. Li, Y.; Tang, C.; Huang, Z.; Hussain, Z.; Are, K.S.; Abegunrin, T.P.; Qin, Z.; Guo, H. Increase in Farm Size Significantly Accelerated Stream Channel Erosion and Associated Nutrient Losses from an Intensive Agricultural Watershed. Agric. Ecosyst. Environ. 2020, 295, 106900. [CrossRef]

57. Li, X.; Zhang, C.; Liu, P.; Liu, J.; Zhang, Y.; Liu, C.; Mu, Y. Significant Influence of the Intensive Agricultural Activities on Atmospheric PM2.5 during Autumn Harvest Seasons in a Rural Area of the North China Plain. Atmos. Environ. 2020, 241, 117844. [CrossRef]

58. Golosov, V.N.; Collins, A.L.; Dobrovolskaya, N.G.; Bazhenova, O.I.; Ryzhov, Y.V.; Sidorchuk, A.Y. Soil Loss on the Arable Lands of the Forest-Steppe and Steppe Zones of European Russia and Siberia during the Period of Intensive Agriculture. Geoderma 2021, 381, 114678. [CrossRef]

59. Dhar, A.R.; Uddin, M.T.; Roy, M.K. Assessment of Organic Shrimp Farming Sustainability from Economic and Environmental Viewpoints in Bangladesh. Environ. Res. 2020, 180, 108879. [CrossRef]

60. Liang, Y.; Wai Hui, C.; You, F. Multi-Objective Economic-Resource-Production Optimization of Sustainable Organic Mixed Farming Systems with Nutrient Recycling. J. Clean. Prod. 2018, 196, 304-330. [CrossRef]

61. von Meyer-Höfer, M.; von der Wense, V.; Spiller, A. Characterising Convinced Sustainable Food Consumers. Br. Food J. 2015, 117, 1082-1104. [CrossRef]

62. Custodio, M.C.; Ynion, J.; Cuevas, R.P.; Samaddar, A.; Ray, A.C.; Mohanty, S.K.; Demont, M. Expert Elicitation Database Capturing Diversity and Cultural Drivers of Food Choice and Nutritional Implications in Eastern India. Data Brief 2020, 33, 106330. [CrossRef] [PubMed]

63. Samaddar, A.; Cuevas, R.P.; Custodio, M.C.; Ynion, J.; Ray, A.C.; Mohanty, S.K.; Demont, M. Capturing Diversity and Cultural Drivers of Food Choice in Eastern India. Int. J. Gastron. Food Sci. 2020, 22, 100249. [CrossRef] [PubMed]

64. Cuevas, R.P.; de Guia, A.; Demont, M. Developing a Framework of Gastronomic Systems Research to Unravel Drivers of Food Choice. Int. J. Gastron. Food Sci. 2017, 9, 88-99. [CrossRef] [PubMed]

65. Civitello, L. Cuisine and Culture: A History of Food and People, 3rd ed.; John Wiley \& Sons: Hoboken, NJ, USA, 2011.

66. Kittler, P.G.; Sucher, K.P.; Nelms, M. Food and Culture; Cengage Learning: Boston, MA, USA, 2011; ISBN 978-0-538-73497-4.

67. Hendry, L.C.; Stevenson, M.; MacBryde, J.; Ball, P.; Sayed, M.; Liu, L. Local Food Supply Chain Resilience to Constitutional Change: The Brexit Effect. Int. J. Oper. Prod. Manag. 2019, 39, 429-453. [CrossRef]

68. Thomé, K.M.; Cappellesso, G.; Ramos, E.L.A.; de Lima, D.S.C. Food Supply Chains and Short Food Supply Chains: Coexistence Conceptual Framework. J. Clean. Prod. 2021, 278, 123207. [CrossRef]

69. Ilbery, B.; Maye, D. Food Supply Chains and Sustainability: Evidence from Specialist Food Producers in the Scottish/English Borders. Land Use Policy 2005, 22, 331-344. [CrossRef]

70. Liu, G.; Agostinho, F.; Duan, H.; Song, G.; Wang, X.; Giannetti, B.F.; Santagata, R.; Casazza, M.; Lega, M. Environmental Impacts Characterization of Packaging Waste Generated by Urban Food Delivery Services. A Big-Data Analysis in Jing-Jin-Ji Region (China). Waste Manag. 2020, 117, 157-169. [CrossRef]

71. López-Rubio, A.; Almenar, E.; Hernandez-Muñoz, P.; Lagarón, J.M.; Catalá, R.; Gavara, R. Overview of Active Polymer-Based Packaging Technologies for Food Applications. Food Rev. Int. 2004, 20, 357-387. [CrossRef]

72. Kastrinos, N.; Weber, K.M. Sustainable Development Goals in the Research and Innovation Policy of the European Union. Technol. Forecast. Soc. Chang. 2020, 157, 120056. [CrossRef]

73. EC. Proposal for a Regulation of the European Parliament and of the Council Establishing Horizon Europe-The Framework Programme for Research and Innovation, Laying Down Its Rules for Participation and Dissemination COM(2018) 435 Final; European Commission: Brussels, Belgium, 2018.

74. Georgescu, M.; Tarcea, M.; Hardmas, R.; Seni, G.; Teodorescu, C.; Szasz, S.; Guiné, R.; Abram, Z. Romanian Population Perception about Food Risk Behavior Starting from Their Social and Cultural Profile. Bull. Univ. Agric. Sci. Vet. Med. Cluj-Napoca. Food Sci. Technol. 2020, 77, 10-16. [CrossRef]

75. Sarić, M.M.; Jakšić, K.; Čulin, J.; Guiné, R.P.F. Environmental and Political Determinants of Food Choices: A Preliminary Study in a Croatian Sample. Environments 2020, 7, 103. [CrossRef]

76. Wongprawmas, R.; Mora, C.; Pellegrini, N.; Guiné, R.P.F.; Carini, E.; Sogari, G.; Vittadini, E. Food Choice Determinants and Perceptions of a Healthy Diet among Italian Consumers. Foods 2021, 10, 318. [CrossRef] 